\title{
Los impuestos en el tratamiento contable y tributario de los contratos de colaboración
}

\author{
Impact of taxes on accounting and tax treatment of \\ collaboration agreements \\ Rafael Castro-Zapata \\ Universidad del Atlántico, Barranquilla, Colombia. \\ Jorge Támara-Name \\ Universidad del Atlántico, Barranquilla, Colombia.
}

\section{Resumen}

Objetivo: caracterizar los impuestos en el tratamiento contable y tributario de los contratos de colaboración. Método: estudio de tipo explicativo, descriptivo, con un diseño no experimental, transeccional, de campo, el cual estuvo constituida por una población de 34 empresas de diferentes sectores económicos. Se obtuvo una muestra de 25 empresas conformadas por dos unidades informantes, en donde se aplicó un instrumento para recoger la información compuesto por 45 reactivos bajo una escala de Likert con alternativas múltiples de respuestas. Este fue validado por (5) expertos y confiabilizado por el método Alfa de Cronbach, arrojando una confiabilidad de 0.89 . Resultados: se encontró que para ejecutar el tratamiento contable-tributario de los contratos de colaboración en Colombia, se requiere vincular aspectos como toma de decisiones, disminución de errores, IVA y retención en la fuente. Conclusiones: se considera relevante que cuando las uniones temporales tengan calidad de responsables de IVA, deberán llevar contabilidad independiente a la de sus partícipes para dar cumplimiento a esta obligación tributaria.

Palabras Clave: Tratamiento contable, tributario, contrato de colaboración.

Clasificacion JEL: M4, M41.

\section{Autores de Correspondencia}

rafaelgcastro@mail.uniatlantico .edu.co

jtamara@mail.uniatlantico.edu. CO

Recibido: 28-01-19

Aceptado: 31-05-19

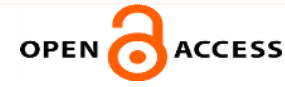

(cc) BY

Copyright (C) 2019

Desarrollo Gerencial

\section{Abstract}

Objective: this paper aims to characterize the impact of taxes on accounting and tax treatment of collaboration agreements. Method: an explanatory, descriptive study with a non-experimental, transactional, field design was conducted; 34 companies from different economic sectors. were taken as reference 25 companies formed by two reporting units were sampled; in order to collect the information, an instrument composed of 45 reagents with a Likert scale using multiple response alternatives was applied. This one was validated by (5) experts and trusted by Cronbach's Alpha method, yielding a reliability of 0.89 . Results: it was found that it is necessary to link aspects such as decision-making, error reduction, VAT and withholding tax, in order to execute the accounting-tax treatment of collaboration contracts in Colombia. Conclusions: temporary unions have the quality of VAT managers, they must keep independent accounts of their participants to comply with this tax obligation, it is considered as relevant.

Keywords: Accounting, tax treatment, collaboration agreement.

JEL Classification: M4, M41.

Como citar este artículo (Apa):

Castro-Zapata, R. \& Támara-Name, J. (2019). Los impuestos en el tratamiento contable y tributario de los contratos de colaboración. Desarrollo Gerencial, 11 (2), 1-16. DOI: https://doi.org/10.17081/dege.11.2.3139 


\section{Introducción}

En la actualidad se ha generado un auge en el mundo empresarial, producto del intercambio comercial, el crecimiento económico, el desarrollo tecnológico y la infraestructura, todo esto asociado a la globalización y a los nuevos mercados estructurales, que además se dan por la alta demanda de bienes y servicios, y las necesidades de las sociedades en general. De esta forma, los empresarios, han entendido que la mejor manera para acceder a múltiples proyectos es bajo la gestión de asociación, es decir, alineándose con empresas u organizaciones que puedan complementarlos, en aquellas áreas que no sean medulares a la suya fin de generar los servicios requeridos por el contexto.

En este sentido, estas organizaciones tienden a la subcontratación o a la asociación en cuanto a poder dirimir sus falencias y necesidades así como también profundizar en esfuerzos especializados, para aumentar su competitividad, optimizar resultados, obtener mayores beneficios al reducir costos y aumentar la eficiencia. Esta subordinación o asociación es entendida como un acuerdo entre dos o más grupos o compañías (socios), que permite apoyar con recursos a un negocio común, los cuales pueden ser materia prima, capital, tecnología, conocimiento del mercado, ventas y canales de distribución, personal, financiamiento o productos.

No obstante, cada empresa, puede seguir operando en forma independiente, sus negocios o empresas sin alterar a la nueva empresa común o Joint Venture como generalmente se le denomina a este tipo de asociación estratégica. Arrubla (2012), enuncia que esta es una de las razones primordiales por las que este tipo de sociedad existe. Pero también afirma que deben correr con el riesgo que se presenten problemas asociados con la contratación de personal, adquisición de materiales e insumos, pero lo más relevante se ha forjado con la doble imposición tributaria nacional e internacional, es decir, los contratos de colaboración al no estar regulado en Colombia, se muestra como un estereotipo contractual, típico o atípico, en el cual dos o más personas jurídicas se asocian con el propósito de realizar una actividad en común asumiendo riesgos compartidos.

En este orden de ideas, Donoso (2014), sostiene que:

El contrato de colaboración es un acuerdo entre dos o más partes que ponen en común sus recursos y colaboración para llevar a cabo una actividad comercial a través de la cual puedan obtener un beneficio mutuo, compartiendo el riesgo que conlleva toda operación empresarial en función de la estructura concreta que acuerden desarrollarla. (p. 3)

De esta manera, López (2008), afirma que:

Los Joint Venture se han utilizado también para transferir tecnología y el Know How <<saber cómo>>, pues se trata de una expresión frecuentemente empleada en los contratos de colaboración empresarial. Sin embargo, no hay uniformidad de criterio para definir este concepto. (p. 465)

Bajo este mismo contexto, Ruiz y Camelo (2009), enuncia que la expresión Joint Venture se usa en la esfera de los negocios internacionales para designar una especie de alianza estratégica, cumplida principalmente por sociedades de capital. 
La doctrina norteamericana concibe el Joint Venture con un criterio más amplio, porque sostiene que es posible la participación de personas naturales y no solo de personas jurídicas. Dentro de este marco, la determinación de las disposiciones tributarias aplicables a este tipo de contrato de Joint Venture, podría depender, de las particularidades del contrato a desarrollar, por lo cual deben evaluarse como generador de procesos los principales aspectos tributarios, los cuales pueden considerarse cuando se pretendan desarrollar las actividades acordadas en dichos contratos, según el país en que se encuentren, en este caso Colombia.

Autores como Cruz (2018), señalan que la apertura económica es beneficiosa cuando se realiza de forma organizada, planeada y con el fin de obtener beneficios mutuos. Martínez, Cardeño, Ramírez y Duran (2018) enuncian que estos procesos colaborativos, se desarrollan a partir de procesos logísticos, los cuales se convierten en determinantes de éxito para las empresas, dado que coordina la utilización de recursos, optimizando los procesos empresariales, en virtud de lograr la reducción de costos.

De este modo, se destaca, que en Colombia se han venido constituyendo una gran diversidad de tipos contractuales en los que se encuentran los nombrados contratos típicos o regulados por la ley y los contratos atípicos o no regulados, donde se ubican los contratos Joint Venture o de colaboración empresarial, puesto que en los últimos tiempos han tomado gran acogida en el mundo ante los procesos de la globalización.

En este orden de ideas, Flórez, Sánchez y Bulla (2013), indican que un proyecto de colaboración empresarial puede concretarse en un contrato de Joint Venture, siempre que no exista un affecttio societatis, es decir, cuando las partes no tienen intención de constituir una nueva persona jurídica. Éste ha sido un tipo de negociación que se ha generado durante muchos años, han ocurrido varios desacuerdos que han inducido a la existencia de doctrina y jurisprudencia, de donde han surgido algunas referencias sobre el particular, a esto Castrillón (2011), lo denomina asociación por necesidad de las partes.

De acuerdo con esto, se le debe dar una mirada al panorama nacional, puesto que los empresarios colombianos, han visto con escepticismo la utilización masiva de este tipo de contratos, viéndose tal actitud reflejada; en el hecho de que no se haya emitido reglamentación al respecto, en este sentido, la dispersión normativa tributaria, incluyendo la doctrinaria en algunos casos discordantes emitida por parte de las autoridades de orden administrativo. Situaciones que na ocurrido producto de la desinformación como consecuencia de la dispersión normativa que gira en torno de estos modelos de negocios en Colombia.

Con la entrada en vigencia de los decretos que reglamentan la Ley 1314 de 2009, concebida como la ley de convergencia hacia estándares internacionales de información financiera y aseguramiento de la información, considera que las normas que se expidan conformen un sistema contable único de alta calidad, comprensible, por cuya virtud los informes contables o los estados financieros, brinden información financiera comprensible, transparente, comparable, pertinente, confiable, útil para la toma de decisiones económicas por parte del Estado, los propietarios, funcionarios y empleados de las empresas, los inversionistas actuales o potenciales y otras partes interesadas, para mejorar la productividad, la competitividad y el desarrollo armónico de la actividad empresarial de las personas naturales y jurídicas, nacionales o extranjeras. 
Con el objetivo de apoyar la internacionalización de las relaciones económicas, el Estado Colombiano, está dirigiendo sus esfuerzos al proceso de convergencia de tales normas de contabilidad, de información financiera y de aseguramiento de la información, con estándares internacionales de aceptación mundial, con las mejores prácticas y con la rápida evolución de los negocios, tales como son las Normas Internacionales de Información Financiera (NIF) y las Normas Internacionales de Auditoria (NIA).

Dentro de este marco, las circunstancias anteriores han provocado inseguridad jurídica en el entorno empresarial que utiliza o que podría utilizar este tipo de contratos y con ello dificultades para cumplir con las obligaciones tributarias de orden formal o sustancial trayendo como efecto colateral que las empresas padezcan las sanciones contempladas en el ordenamiento tributario colombiano, causando ciertos traumatismos como se evidencia en los casos llevados a pleito por vía gubernativa como por la vía contenciosa administrativa, impidiendo en algunos casos que se desaprovechen la oportunidades que brinda el medio y las fortalezas que ofrecen este tipo de contratos.

Adicionalmente las adversidades que han generado las innumerables reformas tributarias junto con la aplicación de los nuevos marcos técnicos financieros, ofrecen un reto para la Gerencia de las empresas en las áreas de contabilidad e impuestos pilares de la organización de la información que la entidad utiliza para la toma de decisiones.

En tal sentido, el ordenamiento jurídico colombiano en el artículo 66 de la ley 488 de 1998 regula el tema para los Consorcios y Uniones temporales, dado que es una norma que debe aplicarse a todas las figuras contractuales así denominadas; y en atención a lo dispuesto por el artículo 338 de la Constitución Nacional de Colombia (1991), que determina la obligatoriedad en que sea la ley quien fije entre otros elementos de la obligación tributaria, el sujeto pasivo; respecto de otras asociaciones que no contraten con el Estado bajo la figura de Consorcios o Uniones temporales.

En este ámbito, el consorcio y la unión y temporal solo están descritos en el estatuto de contratación pública, como una posibilidad para estos entes de jurídicos de presentar propuesta y contratar con el Estado; y por el contrario los Consorcios (en general, que no contratan con el Estado) son una manifestación de los contratos atípicos de Joint Venture, que no están regulados en ninguna norma legal y por lo tanto, no estarían obligatoriamente sujetos a la norma indicada en el apartado anterior.

En consecuencia, en el medio empresarial actual se han identificado vacíos y dudas respecto a los impuestos en el tratamiento contable y tributario de los convenios de colaboración, además del tipo de impuestos que estas deben cancelar según su contexto, por lo tanto el proceso de investigación se convierte en una excelente oportunidad para profundizar y dar una acertada orientación para su adecuado manejo, por lo cual surgió la necesidad de caracterizar los impuestos en el tratamiento contable y tributario de los contratos de colaboración.

\section{Fundamentación teórica}

\section{Tratamiento contable y tributario.}

Dentro de este estudio, es relevante destacar la ventaja del proceso contable en los procesos empresariales, ya que representa un papel importante respecto a los hechos económicos que afectan a una entidad, para brindar 
Rafael Castro-Zapata, Jorge Támara-Name

información confiable, relevante, oportuna y objetiva, a los usuarios de la información financiera. En este sentido, para ejecutar los contratos de colaboración y caracterizar los impuestos, se debe en primer lugar generar la obtención del RUT (registro único tributario) para así contar con un NIT que lo identificará en los aspectos de contratación y tributarios, el proceso se hace a través de la presentación de ciertos requisitos ante la administración tributaria, DIAN, dichos documentos son: el, contrato o convenio de unión temporal o consorcio donde se deben leer bien las clausulas, identificar responsabilidades y obligaciones que se adquieren de forma directa.

Además de las adquiridas por cada uno de sus socios, RUT, copia de documento de identidad y extractos bancarios de quienes lo conforman, certificado de existencia y representación legal (persona natural), cámara de comercio de quien sea persona jurídica, resolución de adjudicación de contrato si este va hacer con una entidad pública, original y copia de los servicios públicos de quien actuará como representante legal.

Asimismo, se plantea que no existe actualmente disposición que obligue a los consorcios y uniones temporales a llevar libros de contabilidad. En el caso de los consorciados o miembros de la unión temporal se debe tener en cuenta la reglamentación aplicable a cada uno. El Consejo Técnico de la Contaduría Pública considera conveniente que los consorcios y uniones temporales lleven contabilidad en forma independiente de sus miembros, donde se discriminen los movimientos de cada miembro del consorcio o unión temporal, lo cual les permite a los administradores y a los consorciados o miembros de la unión temporal conocer los resultados de la gestión, los resultados del contrato, la participación de los miembros en los ingresos costos y gastos y en los derechos, obligaciones, activos, y pasivos.

Con base a lo planeado, Calle y Solórzano (2012) consideran que en los procesos tributarios la prueba contable según es un medio idóneo y eficaz de comprobación, además aporta seguridad para cada uno de los miembros en cuanto al conocimiento patrimonial y el control en la distribución de los ingresos, costos y gastos de las operaciones realizadas por el consorcio o unión temporal. De acuerdo con el mencionado concepto, al momento de constituirse un consorcio o unión temporal se referencia los siguientes elementos.

Analizar las cláusulas del contrato e identificar las responsabilidades y obligaciones que se adquieren en forma directa, así como las adquiridas por cada uno de sus miembros.

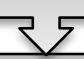

Determinar si el consorcio o unión temporal es responsable del IVA con el objeto de crear las cuentas correspondientes.

\section{S}

Determinar el porcentaje (\%) de participación que tendrán los miembros en los ingresos, costos y gastos.

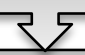

Diligenciar el Registro Único Tributario y solicitar el NIT correspondiente.

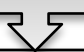

Registrar los libros oficiales del consorcio o de la unión temporal ante la DIAN (Concepto DIAN No. 42416 del 25 de noviembre de 1999) Cada consorcio es autónomo para definir

Si lleva o no contabilidad, y en caso de llevarla, debe organizarla de acuerdo con la estructura del Plan Único de Cuentas que le sea aplicable en desarrollo de los hechos económicos realizados como consecuencia de la ejecución del contrato.

Figura. 1. Referencias para constituir los contratos de colaboración. Proceso de contrato.

Fuente: Elaboración Propia (2017).

Entre las obligaciones tributarias, además de solicitar el Rut, anualmente se deben emitir, por parte del contador y el representante del consorcio, los estados financieros que le son pertinentes, como el balance general, estado de resultados y el estado de flujos de efectivo debidamente certificados (Ley 222, 1995, art. 37) donde se identifique 
Rafael Castro-Zapata, Jorge Támara-Name

claramente la participación correspondiente de cada uno de los consorciados o miembros de la unión temporal, con el fin de incorporar esta información a sus respectivos estados financieros.

\section{Contratos de Colaboración.}

Uno de los elementos bases de los contratos de colaboración, es el hecho de que los individuos tienden a asociarse con otros en busca de alcanzar un beneficio común, de manera tal que puedan alcanzar objetivos comunes o aquellos que convengan a cada uno de acuerdo a la naturaleza de su empresa. Dichas sociedades surgen a través de acuerdos o convenios para afrontar una necesidad que no podrá ser resuelta por cada uno, sino en la medida en que se complementen.

Parra (2005), afirma que el Joint Venture es una forma de asociación interempresarial, que se materializa formalmente por la vía de un contrato, y que en la práctica se manifiesta como un vehículo de cooperación empresarial que actúa como tal en el ámbito mercantil. Dicho de otra manera, constituye un mecanismo, que, a través de la colaboración estratégica entre dos o más empresas, persigue aprovechar la sinergia producida por actuar conjuntamente en una misma dirección, conservando, en lo demás, la independencia de sus partícipes.

Aunado a ello, Peña (2014) expresa que el Joint Venture encuentra su origen comercial en la evolución histórica del imperio británico, cuando se formaban agrupaciones dedicadas a la colonización de nuevos territorios. Tales agrupaciones se encontraban integradas por caballeros aventureros, quienes decidían unir esfuerzos, haciendo algún tipo de aporte y asumiendo riesgos con el fin de obtener utilidades.

Por tal razón, se puede apreciar que no es mucha la diferencia que hay entre las llamadas "Partnership", organizaciones que actualmente se desarrollan en Estados Unidos sin personalidad jurídica-, y entre los Joint Venture que en muchos casos tampoco gozan de esta ficción jurídica, empero, se utilizan como medios asociativos entre empresas para la producción de bienes y servicios.

Desde el punto de vista económico-financiero, Conde (2014) considera que:

El Joint Venture -o como lo denominan otros autores como sociedades mixtas- como un mecanismo para canalizar la inversión extranjera. Asume el autor que los Joint Venture, no sólo significan aporte de flujos de capitales, sino también acceso a la tecnología moderna y desarrollo de capacidad de gestión empresarial. Este tipo de contratos, para su formación, requiere de la existencia de una alta competitividad, es decir debe existir una filosofía de calidad total y planeamiento estratégico, donde las empresas que consideren estos elementos, tendrán mejores condiciones en el futuro para formar tales Joint Venture. (p.54)

Por otra parte, Maguiña (2004) manifiesta que el Joint Venture, se conoce como empresa de riesgo compartido, empresa con participación, empresa conjunta o co-inversión de riesgo. Asimismo, es una forma de cooperación empresarial en un contexto competitivo que actúa como una "asociación empresarial estratégica" entre dos o más empresas nacionales y/o extranjeras, que mediante la integración, interacción y complementariedad de sus actividades y recursos buscan alcanzar propósitos comunes.

En el ordenamiento jurídico colombiano para Corredor, Romero y Zabala (2014), no existe una definición legal del contrato de Joint Venture; sin embargo, dada la aplicación de esta figura contractual en Colombia, la doctrina ha acogido definiciones del derecho comparado y de la jurisprudencia internacional, Friedland y Llano (2010), sugieren que se han definido las características propias de este tipo de contratos. Por lo tanto, a pesar que es un contrato 
atípico en Colombia, se puede canalizar desde las perspectivas de la jurisprudencia, y también se utilizan como referente algunas definiciones.

En tal sentido, Rodríguez (2003), manifestó que a este tipo de contrato se le conoce como de "Riesgo compartido", el mismo tiene como característica que dos o más personas naturales o jurídicas, celebran este contrato con el objeto de realizar una actividad económica específica, es decir, realizar un negocio en conjunto, asumir el riesgo respectivo en común y disfrutar de sus beneficios, por un tiempo determinado, Echeverry (2016), manifestó además que en los consorcios la responsabilidad por las obligaciones tributarias es solidaria, en tanto que en la unión temporal los unidos temporalmente responden en el porcentaje y proporción que indique el proceso de contratación.

Así, Merret y Walzer (2016), consideran que sin la necesidad de constituir una sociedad o persona jurídica. La esencia de este contrato es el objetivo común de las partes, donde la acción es determinada por dos o más emprendedores, sin el ánimo de formar una sociedad.

Se destaca que las legislaciones que no regulan específicamente al contrato de Joint Venture, por lo que hace que dichas empresas fijen en los contratos los derechos y obligaciones que tendrán ambas partes, siendo importante que éstos estén bien definidos. Al no estar regulados por el Estado se denominan como contratos atípicos, destacado por Villasmil, Alvarado, Prieto y Palacios (2018), deben contar con estándares internacionales de aceptación mundial, con las mejores prácticas y con la rápida evolución de los negocios.

De acuerdo a la posición doctrinaria del contrato atípico e innominado (León, 1988, p. 30), el Joint Venture para el ordenamiento legal colombiano, es un contrato atípico en el cual las relaciones ahí contenidas deben ser reguladas internacionalmente por la ley del contrato. Por lo que se afirma que el Joint venture es un contrato atípico dado que carece de normatividad que la estipule, y es innominado porque tienen diferentes prestaciones, y no una única prestación.

Otro aspecto relevante es lo que considera Conde (2014), quien sustenta que el Joint Venture es un contrato oneroso por cuanto cada una de las partes ejecutan prestaciones (es decir aportan algo que se asigne valor económico) a su cargo valoradas en dinero, en tal sentido participan en los beneficios que se obtienen, así como en las perdidas. (p. 59), Es oneroso también por el Due Diligence (Diligencia Debida) que se realiza y que implica además un costo para cada una de las empresas que negocian y que participaran en la conformación del Joint Venture.

En este aspecto, Moreno, Parra, Villasmil, Hernández y Duran (2017), asumen que un contrato cualquiera sea su naturaleza, se concibe como una herramienta capaz de canalizar jurídicamente las necesidades más simples de intercambio.

\section{Impuestos de los contratos de colaboración.}

Las empresas locales e internacionales que ejecuten los contratos de Joint Venture, además de respaldar su tratamiento contable y tributario con los estándares internacionales, también deben responder al régimen impositivo local y nacional, por lo cual está sujeto a diferentes impuestos. 
Impuesto de industria y comercio. En relación con este impuesto, el decreto distrital 400 de 1999 (Estatuto Tributario de Bogotá) indica que:

Es sujeto pasivo del impuesto de industria y comercio la persona natural o jurídica, o la sociedad de hecho, que realice el hecho generador de la obligación tributaria. Son contribuyentes del impuesto de industria y comercio, las sociedades de economía mixta y las empresas industriales y comerciales del Estado. Los profesionales independientes son contribuyentes del impuesto de industria y comercio y su impuesto será igual a las sumas retenidas por tal concepto. (Art. 1)

Respecto de esta disposición, cabe mencionar un antecedente jurisprudencial el cual analizó la aparente similitud que para algunos puede presentarse entre el consorcio y la sociedad de hecho, considerando finalmente que las obligaciones de la sociedad de hecho no eran aplicables a los consorcios, dada la naturaleza jurídica de cada uno de los mismos. Es así como la Sala de lo contencioso administrativo del Consejo de Estado, sección cuarta, en sentencia del 26 de marzo de 2009 (consejera ponente Ligia López Díaz, radicado 16782), citada por Flórez et al. (2013) hizo las siguientes afirmaciones:

"...En relación con el objeto y la causa, los contratos societarios y los acuerdos de consorcios son diferentes, pues la finalidad de los consorcios está necesariamente ligada a un contrato estatal, bien sea para su adjudicación, celebración o sobre todo su ejecución..."

"...El acuerdo mediante el cual se constituye el consorcio es un negocio jurídico típico, pues obedece a la definición legal del artículo 70 de la Ley 80 de 1993..."

"... De otra parte, tampoco se puede desconocer que la intención del legislador cuando ha gravado a los consorcios, ha sido hacerlo de manera expresa y no por vía analógica asimilándolo a las sociedades de hecho, como ocurre en el caso del artículo 66 de la Ley 488 de 1998, que adicionó el artículo 437 del Estatuto Tributario Nacional.

En consecuencia, la Sala ha reiterado que los consorcios no se pueden confundir con sociedades de hecho, no son sujetos pasivos del impuesto de industria y comercio y no están obligados a declarar, ni a pagar suma alguna por tal concepto. Los sujetos pasivos en consecuencia, son las personas naturales o jurídicas que lo integran.

Tomando en cuenta la información y atendiendo a lo indicado por el Consejo de Estado y lo adaptado por la citada jurisprudencia se lleva a establecer que los demás contratos de Joint Venture que son completamente atípicos (consorcios privados o Joint Venture) no serían sujetos pasivos de este impuesto, porque la ley no los ha definido como tales, y actualmente se sustentan los siguientes: impuestos territoriales que hacen referencia a los consorcios, a saber:

Artículo 54 de la ley 1430 de 2010. Son sujetos pasivos de los impuestos departamentales y municipales, las personas naturales, jurídicas, sociedades de hecho, y aquellas en quienes se realicen el hecho gravado, a través de consorcios, uniones temporales, patrimonios autónomos en quienes se figure el hecho generador del impuesto.

Artículo 54 de la ley 1607 de 2012. Los sujetos pasivos de los impuestos departamentales y municipales son las personas naturales, jurídicas, sociedades de hecho y aquellas en quienes se realicen el hecho gravado a través de consorcios, uniones temporales, patrimonios autónomos en quienes se figure el hecho generador del impuesto. 
Asimismo, el Parágrafo $2^{\circ}$ frente al impuesto a cargo de los patrimonios autónomos los fideicomitentes y/o beneficiarios, afirma que son responsables por las obligaciones formales y sustanciales del impuesto, en su calidad de sujetos pasivos. Siguiendo con Flórez et al. (2013), en los contratos de cuenta de participación el responsable del cumplimiento de la obligación de declarar es el socio gestor; en los consorcios, socios o partícipes de los consorcios, uniones temporales, lo será el representante de la forma contractual. Todo lo anterior, sin perjuicio de la facultad tributaria respectiva de señalar agentes de retención frente a tales ingresos.

Impuesto sobre la renta. La situación actual de los consorcios y uniones temporales por expresa disposición legal es que no son contribuyentes del impuesto sobre la renta, conforme a lo establece el artículo 18 del Estatuto Tributario, por lo tanto, los consorcios y uniones temporales que contratan con el Estado, a pesar de estar referidos en la ley 80 de 1993 no son sujetos pasivos del impuesto de renta, dado que la norma de la citada ley ha sido derogada y existe la prohibición tributaria; los demás contratos de Joint Venture y consorcios privados tampoco estarán sujetos al impuesto en mención, por la prohibición de la norma tributaria y además porque se trata de contratos atípicos que no tienen una definición legal para establecer claramente que se debe entender por estos y quien será el sujeto pasivo de esa asociación, sustentado en este sentido por Zapata, Barona, \& Esplugues (2010).

Impuesto sobre las ventas. Respecto de este impuesto, el artículo 66 de la ley 488 de 1998 (por la cual se expiden normas en materia tributaria y se dictan otras disposiciones fiscales de las entidades territoriales) establece que:

...para que se considere responsable del IVA los consorcios y uniones temporales cuando en forma directa sean ellos quienes realicen actividades gravadas.

Sin embargo, cabe aclarar que haciendo un análisis de la figura del consorcio con la norma examinada se advierte que no es fácil determinar en qué casos actúa directamente el consorcio, teniendo en cuenta que no tiene capacidad jurídica frente a terceros y únicamente en el caso que contrate con el Estado cuenta con capacidad para presentar propuesta y contratar con él.

En particular según Flórez et al. (2013) se advierte que los bienes y servicios que provea el consorcio o unión temporal directamente y estén gravados con IVA, conforme a la citada disposición deben ser declarados por el Consorcio o Unión temporal; Zarate (2011), no obstante, cuando sea el Consorcio o Unión temporal, quien pague por bienes o servicios gravados con IVA, la situación cambia, dado que conforme lo dispone la ley, solo cuando el Consorcio actúa directamente podría descontar ese IVA pagado al tercero, es decir, cuando el tercero facture a nombre del consorcio.

De conformidad con el ordenamiento jurídico colombiano, el artículo 66 regula el tema para los Consorcios y Uniones temporales, se podría considerar que es una norma que debe aplicarse a todas las figuras contractuales así denominadas; sin embargo, no obstante, en atención a lo dispuesto por el artículo 338 de la Constitución Nacional vigente, que determina la obligatoriedad en que sea la ley quien fije entre otros elementos de la obligación tributaria, el sujeto pasivo; respecto de otras asociaciones que no contraten con el Estado bajo la figura de Consorcios o Uniones temporales. 
Con relación a lo anterior, no sería aplicable la citada disposición, siendo que el consorcio y la unión y temporal solo están descritos en el estatuto de contratación pública, como una posibilidad para estos entes de jurídicos de presentar propuesta y contratar con el Estado; y por el contrario los Consorcios (en general, que no contratan con el Estado) son una manifestación de los contratos atípicos de Joint Venture, que no están regulados en ninguna norma legal y por lo tanto, no estarían obligatoriamente sujetos a la norma.

\section{Método}

La investigación se encuentra influenciada bajo el paradigma positivista, de tipo descriptiva, explicativa. Bajo un diseño no experimental, transeccional, de campo. La población quedó representada por veinticinco (25) empresas ubicadas en Barranquilla.

Asimismo, se utilizó un cuestionario con cuarenta y cinco (45) preguntas con cinco opciones de respuestas tipo escala Likert, validada por 5 expertos. Para analizar los datos, se utilizó la estadística descriptiva e inferencial considerando las medias alcanzadas por los indicadores, dimensiones y variables.

Igualmente, se empleó la comparación de medias mediante la técnica del ANOVA, y la Prueba Post Hoc de Tukey lo cual permitió reubicar la posición de los indicadores, así como también la "T" de Student para muestras independientes entre dimensiones y la regresión lineal simple. Asimismo, los datos se analizaron sustentados en un baremo de interpretación.

\section{Resultados y discusión}

Tabla 1.

Régimen impositivo de los Contratos

\begin{tabular}{ccc}
\hline INDICADORES & MEDIA & CATEGORÍA \\
\hline IMPUESTO DE INDUSTRIA Y COMERCIO & 4,19 & ALTO \\
\hline IMPUESTO SOBRE LA RENTA & 3,61 & ALTO \\
\hline IMPUESTO SOBRE LAS VENTAS & 4,27 & MUY ALTO \\
\hline TOTAL & 4,02 & ALTO \\
\hline
\end{tabular}

Nota. Fuente: Elaboración Propia (2018).

En función de caracterizar los impuestos en el tratamiento contable y tributario de los contratos de colaboración, se observa que el primer reactivo impuesto de industria y comercio, presenta una media de 4.19, ubicándolo en el escalafón alto en el intervalo $(3,41<4,20)$, determinando que es importante que existan impuestos relacionados directamente con este tipo de contratos de colaboración.

Seguidamente en el análisis, se presenta el segundo reactivo concerniente impuesto sobre la renta, el cual presenta una media de 3,61, ubicándolo en el nivel alto en el intervalo $(3,41<4,20)$, traduciendo la importancia que tienen los impuestos sobre la renta como impuesto a cancelar dentro de los contratos de colaboración. Al continuar con el análisis de este elemento, se observa el tercer reactivo Impuesto a las ventas, presentando una media de 4,27, ubicándolo en el escalón de muy alto en el intervalo $(4.21<5,00)$, verificando la relevancia de este impuesto para concretar dichos contratos, en el proceso de transformación de los recursos obtenidos a través de la inversión. 
Por último, el análisis de la dimensión referente a los impuestos en el tratamiento contables de los Contratos, se evidencia una media de 4,02, ubicándolo en el escalafón alto en el intervalo $(3.41<4,20)$, indicando la determinación de los impuestos como un nivel de responsabilidad de las empresas con el Estado a través de los aportes que recibe producto de dichos impuestos. De acuerdo con esto, se verificó la normalidad de la dimensión obteniéndose el resultado de una curva gaussiana normal por cuanto su nivel de significancia 0,000 es menor que 0,05 (cota referencial), destacando el hecho de la validación de la normalidad con la prueba de Shapiro-Wilk, tal como se muestra en la Tabla 2.

Tabla 2.

Prueba de Normalidad

\begin{tabular}{ccccccc}
\hline \multirow{2}{*}{ INVERSIÓN } & \multicolumn{3}{c}{ Kolmogorov-Smirnov $^{\mathrm{a}}$} & \multicolumn{3}{c}{ Shapiro-Wilk } \\
\cline { 2 - 6 } & Estadístico & $\mathrm{gl}$ & Sig. & Estadístico & gl & Sig. \\
\hline IMPUESTO DE INDUSTRIA Y COMERCIO &, 348 & 25 &, 000 &, 749 & 25 &, 000 \\
\hline IMPUESTO SOBRE LA RENTA &, 341 & 25 &, 000 &, 692 & 25 &, 000 \\
\hline IMPUESTO SOBRE LAS VENTAS &, 328 & 25 &, 000 &, 755 & 25 &, 000 \\
\hline
\end{tabular}

Nota. Fuente: Elaboración Propia (2018).

Una vez obtenida la prueba de normalidad para la dimensión "normas", se obtuvo luego de aplicada la técnica estadística Análisis de la Varianza (ANOVA) en la Variable tratamiento contable y tributario de los contratos de colaboración, la significancia obtenida por los indicadores de la dimensión obtuvo un nivel de significancia de 0,00; siendo este valor menor que 0,05 $(0,000<0,05$; cota referencial), lo cual permite inferir que existen diferencias altamente significativas entre los indicadores comparados, evidenciando que no todos tienen el mismo grado de presencia dentro de esta dimensión. (Tabla 3).

Tabla 3.

ANOVA Impuestos dentro del tratamiento contable

\begin{tabular}{|c|c|c|c|c|c|}
\hline & Suma de cuadrados & $\mathrm{gl}$ & Media cuadrática & $\mathrm{F}$ & Sig. \\
\hline Entre grupos & 17,053 & 2 & 8,527 & 25,664 &, 000 \\
\hline Dentro de grupos & 48,840 & 147 & ,332 & & \\
\hline Total & 65,893 & 149 & & & \\
\hline
\end{tabular}

Nota. Fuente: Elaboración Propia (2018).

Adicionalmente se aplicó el test HSD (Honestly-significant-difference) de Tukey a fin de comparar pruebas de múltiples rangos, en los cuales se evidencian las diferencias entre los indicadores de la dimensión normas que regulan los contratos de colaboración en Colombia, igualmente la homocedasticidad de las varianzas entre los indicadores.

(Tabla 4).

Tabla 4.

HSD de Tukey. Régimen impositivo

\begin{tabular}{|c|c|c|c|}
\hline \multirow{2}{*}{ Impuestos } & \multirow{2}{*}{$\mathrm{N}$} & \multicolumn{2}{|c|}{ Subconjunto para alfa $=0.05$} \\
\hline & & 1 & 2 \\
\hline Impuesto de industria y comercio & 25 & 3,5000 & \\
\hline Impuesto sobre la renta & 25 & & 4,1600 \\
\hline Impuesto sobre las ventas & 25 & & 4,2600 \\
\hline Sig. & & 1,000 & 662 \\
\hline
\end{tabular}

Nota. Fuente: Elaboración Propia (2018).

Los impuestos que deben responder las empresas asociadas a los contratos de colaboración, se sustentan en normas tributarias, las cuales son un claro ejemplo de inestabilidad jurídica, no solamente por las múltiples reformas 
legislativas que suman siete desde 1989, sino por los vacíos normativos, a este respecto Maguiña (2004) afirma que en el ordenamiento jurídico colombiano no existe una definición legal del contrato de Joint Venture; sin embargo, dada la aplicación de esta figura contractual en Colombia, la doctrina ha acogido definiciones del derecho comparado y de la jurisprudencia internacional, donde han definido las características propias de este tipo de contratos. Sin embargo, hubo intento de regulación del tema, por lo cual vale la pena mencionar que se tenía previsto la creación del contrato de agrupación y el de unión transitoria.

Impuesto sobre la renta. En materia del impuesto sobre la renta, el inciso $3^{\circ}$ del artículo 13 del Decreto 624 de 1989 señala que los consorcios son contribuyentes del impuesto sobre la renta y complementarios y para tal efecto, se asimilan a las sociedades limitadas. Esta norma fue acusada de inexequible ante la Corte Suprema de Justicia, porque violaba los artículos 2, 43 y 55 de la Constitución Nacional de 1886, por cuanto dicha disposición se tornaba imprecisa e incierta, siendo que no existía definición legal del concepto "consorcio", lo cual dejaba al arbitrio de los funcionarios de impuestos la aplicación de la norma para que por vía de interpretación dispusieran acerca de un elemento fundamental de la tributación, como lo es la determinación del sujeto pasivo.

La situación actual de los consorcios y uniones temporales por expresa disposición legal es que no son contribuyentes del impuesto sobre la renta, conforme a lo establece el artículo 18 del Estatuto Tributario, por lo tanto, los consorcios y uniones temporales que contratan con el Estado, a pesar de estar referidos en la ley 80 de 1993 no son sujetos pasivos del impuesto de renta, dado que la norma de la citada ley ha sido derogada y existe la prohibición tributaria; los demás contratos de Joint Venture y Consorcios privados tampoco estarán sujetos al impuesto en mención, por la prohibición de la norma tributaria y además porque se trata de contratos atípicos que no tienen una definición legal para establecer claramente que se debe entender por estos y quien será el sujeto pasivo de esa asociación.

Impuesto sobre las ventas. En este ámbito, el artículo 66 de la ley 488 de 1998 establece que: ...para que se considere responsable del IVA los consorcios y uniones temporales cuando en forma directa sean ellos quienes realicen actividades gravadas. Sin embargo, cabe aclarar que haciendo un análisis de la figura del consorcio con la norma examinada, Carvajal (2016), advierte que no es fácil determinar en qué casos actúa directamente el consorcio, teniendo en cuenta que no tiene capacidad jurídica frente a terceros y únicamente en el caso que contrate con el Estado cuenta con capacidad para presentar propuesta y contratar con él.

En particular, según Flórez et al. (2013) se advierte que los bienes y servicios que provea el consorcio o unión temporal directamente y estén gravados con IVA, conforme a la citada disposición deben ser declarados por el Consorcio o Unión temporal; sin embargo cuando sea el Consorcio o Unión temporal, quien pague por bienes o servicios gravados con IVA, la situación cambia, dado que conforme lo dispone la ley, solo cuando el Consorcio actúa directamente podría descontar ese IVA pagado al tercero, es decir, cuando el tercero facture a nombre del consorcio.

De conformidad con el ordenamiento jurídico colombiano, el artículo 66 regula el tema para los Consorcios y Uniones temporales, se podría considerar que es una norma que debe aplicarse a todas las figuras contractuales así denominadas; sin embargo, no obstante, en atención a lo dispuesto por el artículo 338 de la Constitución Nacional, que determina la obligatoriedad en que sea la ley quien fije entre otros elementos de la obligación tributaria, el sujeto 
pasivo; respecto de otras asociaciones que no contraten con el Estado bajo la figura de Consorcios o Uniones temporales.

En consecuencia, Peña (2014), manifiesta que en Colombia no ha existido un desarrollo integral de esta figura contractual del Joint Venture, y, además, la existente, es en materia de contratación pública por medio de la figura del consorcio y las uniones temporales. Además que, en la jurisprudencia, la Corte Suprema de Justicia no ha manejado conflictos sobre esta figura, sino que, de manera llana, esa Corporación se ha dedicado a indicar que los Joint venture están dentro de los denominados 25 atípicos, y por tal razón, deben ser manejados por analogía, lo que ha llevado a acudir a la costumbre internacional que hay sobre su manejo; y por parte de la Corte Constitucional.

\section{Conclusiones}

Este estudio se orientó a caracterizar los impuestos en el tratamiento contable y tributario de los contratos de colaboración, destacando la inexistencia de una regulación concreta sobre el tema, gracias al uso de la costumbre mercantil, los lineamientos generales del Código Civil y de la dinámica de estas clases de negocios, se ha podido llegar a utilizar por parte de las compañías sin ningún problema ni restricción, lo que permite inferir que más allá de la falta de regulación, que se itera, es una situación notable, el problema se traslada a la falta de información del mismo, pudiéndose promocionar a través de su reglamentación por el constituyente secundario.

Dentro de este orden de ideas, el impuesto sobre la renta y sus complementarios, son impuestos directos que gravan la percepción de ingresos que no estén expresamente excluidos del gravamen, susceptibles de aumentar el patrimonio del contribuyente, en un período gravable determinado. asimismo, el estatuto tributario establece que las uniones temporales no forman parte de los contribuyentes al impuesto sobre la renta, sin embargo, los miembros de estos mismos, están en obligación de incluir en su contabilidad ingresos, costos y deducciones correspondientes, para declarar de manera independiente en relación a su participación de la unión temporal.

Por otra parte, se encuentra normada la retención en la fuente, sin embargo, cuándo los consorcios o uniones temporales son de estructura simple, esto quiere decir, qué cada uno de sus miembros desarrolla una actividad específica estipulada en el contrato sin existencia de ingresos, costos o gastos comunes, no existirá una distribución proporcional para la imputación de estos, sino correspondiente a la actividad de cada uno de los partícipes.

Además son agentes de retención, las entidades de derecho público, los fondos de inversión, los fondos de valores, los fondos de pensiones de jubilación e invalidez, los consorcios, las comunidades organizadas, las uniones temporales y las demás personas naturales o jurídicas, sucesiones ilíquidas y sociedades de hecho, que por sus funciones intervengan en actos u operaciones en los cuales deben, por expresa disposición legal, efectuar la retención del tributo correspondiente, según lo planteado por el Ministerio de Hacienda y Crédito Público.

De acuerdo con esto, la unión temporal debe practicar las retenciones en la fuente a título de impuesto sobre la renta, presentar la declaración mensual, consignar los valores retenidos y certificar las retenciones realizadas. Para el cumplimiento de estas obligaciones propias de su calidad de agente retenedor del impuesto sobre la renta, la unión temporal debe obtener su número de identificación tributaria NIT. 
En cuanto, al impuesto sobre las ventas, este impuesto es de gran importancia en Colombia, esto por sus bajos costos de administración y su alta participación en los niveles de recaudo, él impuesto al valor agregado es de naturaleza indirecta, Qué grava la venta y la importación de bienes corporales muebles y la prestación de servicios, en el territorio colombiano, sin tener en cuenta la calidad de las partes que realizan la operación.

\section{Referencias}

Alcaldía Mayor de Bogotá. (28 de junio de 1999). Articulo 1 [Decreto 400 de 1999]. Recuperado de https://www.alcaldiabogota.gov.co/sisjur/normas/Norma1.jsp?i=1855

Arrubla, J. (2012). Contratos Mercantiles Contratos Atípicos. $7^{a}$ ed. Bogotá: Legis Editores.

Calle, A. \& Solórzano, Y. (2012). Guía para el adecuado manejo de consorcios y uniones temporales según la normatividad vigente en Colombia. (Trabajo de grado especialización, Universidad de Medellín). Recuperado de https://n9.cl/rbqr

Carvajal-López, Y. (2016). Régimen tributario aplicable a los contratos de unión temporal en Colombia (Tesis de pregrado, Universidad Militar Nueva Granada. Recuperado de http://hdl.handle.net/10654/7909

Castrillón, M. (2011). De Los Contratos Mercantiles. En Miranda, L., Vela, P. \& Príes, A. (Comp.). Tratado de Derecho Mercantil (pp. 658-664). México: Porrúa.

Conde, J. (2014). Análisis del contrato de Joint Venture y sus mecanismos de financiamiento. Vox Juris, 271), 47-78. Recuperado de https://www.aulavirtualusmp.pe/ojs/index.php/VJ/article/view/30

Congreso de Colombia. (13 de julio de 2009). Ley de Convergencia hacia normas internacionales de información financiera y Aseguramiento de la Información. [Ley 1314 de 2009]. DO: 47.409.

Congreso de Colombia. (24 de diciembre de 1998). Ley en materia tributaria y otras disposiciones fiscales de las Entidades Territoriales. [Ley 488 de 1998]. DO: 43.460.

Congreso de Colombia. (29 de diciembre de 2010). Artículo 54. Ley normas tributarias de control y para la competitividad. [Ley 1430 de 2010]. DO: 47.937.

Congreso de Colombia. (26 de diciembre de 2012). Artículo 54. Ley normas en materia tributaria. [Ley 1607 de 2012]. DO: 48.655.

Corredor-Olaya, J., Romero-Garzón, J. \& Zabala-Trujillo, D. (2014). El contrato de Joint Venture en Colombia, realidad jurídica en el sector privado a través de casos concretos. (Trabajo de grado especialización, Pontificia Universidad Javeriana). Recuperado de https://repository.javeriana.edu.co/handle/10554/14884?mode=full

Constitución Política de Colombia [Const.] (1991) Artículo 338. [Título XII]. Recuperado de http://www.constitucioncolombia.com/titulo-12/capitulo-1/articulo-338 
Congreso de Colombia. (20 diciembre de 1995) Artículo 37 [Capítulo VI]. Ley General de Educación. [Ley 115 de 1194] Ley de sociedades comerciales. [Ley 222 de 1005]. DO: 42.156.

Cruz-Negrete, J. (2018). Acuerdos comerciales de Colombia: Impactos en balanza comercial e inversión extranjera directa. Desarrollo Gerencial, 10(1), 48-63. DOI: https://doi.org/10.17081/dege.10.1.2970

Donoso, R. (2014). "Joint Venture" o contrato de colaboración empresarial explicación, ventajas y desventajas de la colaboración estratégica. Revista Digital Nuevo Derecho: Creare Scientia In IUS, 11-11. Recuperado de http://www.nuevoderecho.cl/wp-content/uploads/Joint-Venture.pdf

Etcheverry, R. (2016). Contratos asociativos, negocios de colaboración y consorcios. $1^{a}$ ed. Bogotá: Astrea SAS.

Flórez, A., Sánchez, D. \& Bulla, J. (2013). ¿Cuál es la regulación tributaria de los contratos de Joint venture en Colombia?. (Tesis de Grado Especialización, Pontificia Universidad Javeriana). Recuperado de https://repository.javeriana.edu.co/bitstream/handle/10554/14912/FlorezArenasAngelaMarcela2013.pdf?sequ ence $=1$ \&isAllowed $=\mathrm{y}$

Friedland, P. \& Llano, R. (2010). Cláusulas de arbitraje para contratos internacionales. Buenos Aires: Editorial Abeledo Perrot.

León, H. (1988). Contratos Mercantiles-Joint Venture. Revista Peruana de Derecho de la Empresa, (39), 104-124.

López, F. (2008). El contrato de franquicia internacional. Bogotá: Editorial Temis.

Maguiña, F. (2004). Joint venture: estrategia para lograr la competitividad empresarial. Córdoba: El Cid Editor

Martínez-Ventura, J., Cardeño-Portela, E., Ramírez-Cardeño, W., \& Durán, S. (2017). Liderazgo transformacional como estrategia de adaptación en la gestión logística empresarial. Desarrollo Gerencial, 9(2), 140-157. DOI: https://doi.org/10.17081/dege.9.2.2980

Merrett, C. \& Walzer, N. (2016). Cooperatives and Local Development: Theory and Applications for the 21st Century. $1^{\text {a }}$ ed. Routledge: Taylor \& Francis Company.

Moreno, Z., Parra, M., Villasmil-Molero, M., Hernández, B. \& Duran, S. (2017). Importancia del Pensamiento Estratégico y Acciones Estratégicas para impulsar el emprendimiento social en las universidades venezolanas. Revista Espacios, 38(45). Recuperado de https://www.revistaespacios.com/a17v38n45/a17v38n45p04.pdf

Parra, J. (2005). Sociedades extranjeras y negocios internacionales. Bogotá: Ediciones Jurídicas Gustavo Ibáñez.

Peña, L (2014). De los contratos mercantiles nacionales e internacionales, Bogotá, Ecoe Ediciones.

Peña, L. (2014). De las sociedades comerciales. Bogotá: Eco Ediciones.

Presidencia de la República (1989). Estatuto Tributario [Decreto Extraordinario 624 de 1989]. 
Rodríguez, G. (2003). Nuevos Contratos Estatales: Comentarios a la ley 80 de 1993 con doctrinas y jurisprudencias. Bogotá: editorial jurídica wilches.

Ruiz, A. \& Camelo, M. (2009). Innovation through Joint Ventures. Implications and Role of the Top Management Team. AD-minister, (14), 161-194. Recuperado de http://publicaciones.eafit.edu.co/index.php/administer/issue/view/36

Villasmil-Molero, M., Alvarado-Peña, L., Prieto-Pulido, R. \& Palacios-Arrieta, A. (2018). Procedimiento del arbitraje tributario en el contexto venezolano. Revista Venezolana de Gerencia, 23(81), 65-87. http://www.produccioncientifica.luz.edu.ve/index.php/rvg/article/view/23469

Zapata-Arbeláez, A. Barona, S. \& Esplugues, C. (2010). El arbitraje interno e internacional en Latinoamérica. Regulación presente y tendencias del futuro. Bogotá: Universidad Externado de Colombia.

Zarate-Flores, A. (2011). Efectos tributarios de los contratos de colaboración económica consorcio y unión temporal. (Ensayo de grado especialización, Universidad de la Sabana). Recuperado de https://intellectum.unisabana.edu.co/bitstream/handle/10818/1348/ANDREA\%20DEL\%20PILAR\%20ZARATE \%20FLOREZ.pdf?sequence=1\&isAllowed=y 